\title{
Advances in blends preparation based on electrically conducting polymer
}

\author{
Jolly Bhadra ${ }^{1}$ - Noora Al-Thani ${ }^{1}$ \\ Received: 2 October 2018 / Accepted: 21 February 2019 / Published online: 1 April 2019 \\ (C) The Author(s) 2019
}

\begin{abstract}
This work presents an extensively detailed study on preparation and performance of four different hydrochloric acid-doped polyaniline (PANI) blends. The blends are obtained by changing four different polymers, viz. polyvinyl alcohol (PVA), polystyrene (PS), polyvinyl chloride (PVC), and sodium alginate (SA) keeping PANI concentration constant. Finally, the blend films deposited on substrates are used to characterize the surface, structural morphology, chemical interaction (SEM and FTIR), thermal properties (TGA and DSC), and mechanical properties by tensile testing. The morphological analysis shows uniform chemical blending of PANI with all three insulating matrices except in PVC matrix. FTIR and TGA results also suffice the fact that PANI particle has a chemical interaction with polymer backbones. Electrical conductivity study of PANI blend reveals that PANI-PVA forms the highest conducting blend with the conductivity of order of $10^{-2} \mathrm{~S} / \mathrm{cm}$ and PANI-PVC has the lowest at $10^{-13} \mathrm{~S} / \mathrm{cm}$.
\end{abstract}

Keywords Conduction polymer $\cdot$ Flexibility $\cdot$ Blend $\cdot$ Mechanical property $\cdot$ Electrical property

\section{Introduction}

Encouraged by the growing requirement of portable and foldable electronic devices, the need of materials with inherent flexibility is on high demand. The literature is rich in this domain [1-4]. Flexibility, being the fundamental criteria, in polymeric materials is usually a preferred choice. Although polymers are mostly known for their use in electrical and thermal insulation $[5,6]$ industry, they have a too strong footstep in electronic industry where they are used as conducting materials $[7,8]$. For example, conducting form of polymers is very useful in helping dissipate and shield off electrostatic charge from rubber and plastic parts of any electronic instrument and their protection from the effects of electromagnetic waves $[9,10]$. These are some of the solid rationale for material scientists to work towards designing a hybrid polymeric

Noora Al-Thani

n.al-thani@qu.edu.qa

Jolly Bhadra

jollybhadra@qu.edu.qa

1 Centre for Advanced Materials, Qatar University, Doha, Qatar material combined with both electrical and mechanical properties [11-15].

The basic approach to convert polymers from insulating to conducting form is by using conducting fillers, such as metallic powders and fibers, carbon nanotube, graphene, and conducting polymer [16-20]. Among all conducting polymers, conducting filler has received a great deal of attention for advanced applications including field effect transistors, corrosion protection actuators, and sensors $[9,11,13$, 21, 22]. Similarly, polyaniline (PANI) is quite suitable for its distinguished characteristics such as environmental stability in the conducting form, ease and low cost synthesis, high yield, and relatively, high conductivity [19]. The preparation process of polymer blend can broadly be divided into two: (1) in situ method, in which aniline is polymerized inside a matrix polymer [23], and (2) solution casting method, adding prepared PANI to the polymer matrix [24]. Each method has its own set of pros and cons. For instance, synthetic route is more preferable (1) in order to produce inexpensive conducting composites (as aniline is cheaper than PANI), (2) when thin highly conductive polymer layer is required, etc. This synthetic route is also useful to obtain blends with homogeneous surface and low percolation threshold. On the contrary, blending method is useful for mass-scale production. 
In this study, we investigate the effects of PANI blending as a conducting filler material with four different conventional polymers viz., polyvinyl alcohol (PVA), polystyrene (PS), polyvinyl chloride (PVC), and sodium alginate (SA) on its morphological, thermal, mechanical, and electrical properties. PVA and SA are two water-soluble polymers, whereas PS and PVC are two commodity polymers with hydrophobic nature. All these polymers are inexpensive, non-toxic, and abundantly used in domestic industries. Textile, paper, food, pharmaceutical, and packaging industries make abundant use of PVA and SA [25-27]. On the other hand, PVC and PS are extensively used in different types of home appliance industries, building materials, automobile industries, etc. [28] (https:// www.britannica.com/science/polyvinyl-chloride). Considering all the advantages, extensive amount of research has already been done on blending of PANI with these conventional polymers in order to increase the spectrum of applications [29-34]. Through this paper, we have made a sincere effort to develop a comparative investigation on blending PANI with PVA, PS, PVC, and SA. We utilize both in situ and solution casting methods to prepare the blends; then, their morphological, mechanical, thermal, and electrical properties are compared with each other. We have also used broadband dielectric spectroscopy to present an in-depth investigation of the electrical transport behavior of HCL doped into four different PANI blends.

\section{Materials and methods}

This section describes the polymers, different chemicals used, and the methods adopted for characterizations of polymer blends.

\subsection{Materials}

All the chemicals and polymers used in this experiment are obtained from Merck and Sigma chemical company and are of very high purity (99.9\%). Aniline is purified by repeated distillation under vacuum and stored at low temperature prior to use. The oxidizing agent ammonium persulfate and acid are used as received. All the solutions are prepared using doubledistilled water during the synthesis.

\subsection{Sample preparation}

Pure PANI is obtained using dispersion polymerization technique defined in the literature $[20,22]$. The polymerization is initiated by adding $10 \mathrm{ml}$ of $1 \mathrm{M}$ ammonium persulfate drop- wise to the solution of aniline $(0.25 \mathrm{~g})$ in aqueous $1 \mathrm{M} \mathrm{HCl}$ $(1.75 \mathrm{~g})$ under constant stirring. The bath temperature is maintained at $0-5{ }^{\circ} \mathrm{C}$. After complete addition of the oxidant, the reaction is kept in constant stirring for the next $24 \mathrm{~h}$. The reaction mixture turns into a bluish green homogeneous mixture indicating the completion of polymerization reaction. The resulting precipitate is filtered and washed with deionized water and methanol until the filtrate becomes colorless to remove any oligomer or unreacted oxidant. The powder of PANI is dried under reduced pressure at $40{ }^{\circ} \mathrm{C}$ for $24 \mathrm{~h}$. Figure 1 provides the graphical representation of all the four blend preparation processes.

\subsubsection{PANI-PVA blend}

To prepare PANI-PVA blend, chemical polymerization of aniline is carried out in aqueous acidic media $(\mathrm{pH}-4)$ containing PVA ( $2 \mathrm{~g})$. In this process, the acidic solution of PVA is maintained in $0-5^{\circ} \mathrm{C}$. While the sample is being stirred, ammonium persulfate of constant molar ratio to aniline is added drop wise over a period of $1 \mathrm{~h}$. The solution turns green indicating the formation of PANI, and the reaction mixture is stirred continuously for a period of $24 \mathrm{~h}$ maintaining at the same

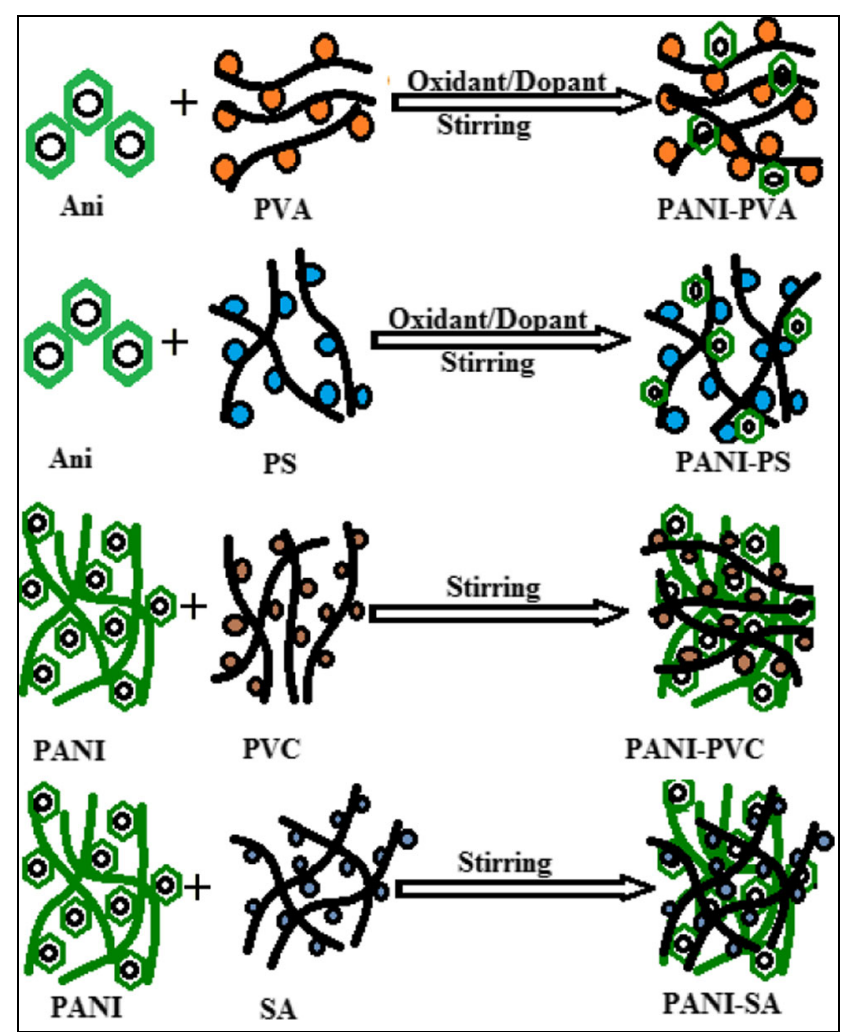

Fig. 1 Graphical representation of four types of blend preparation methods 

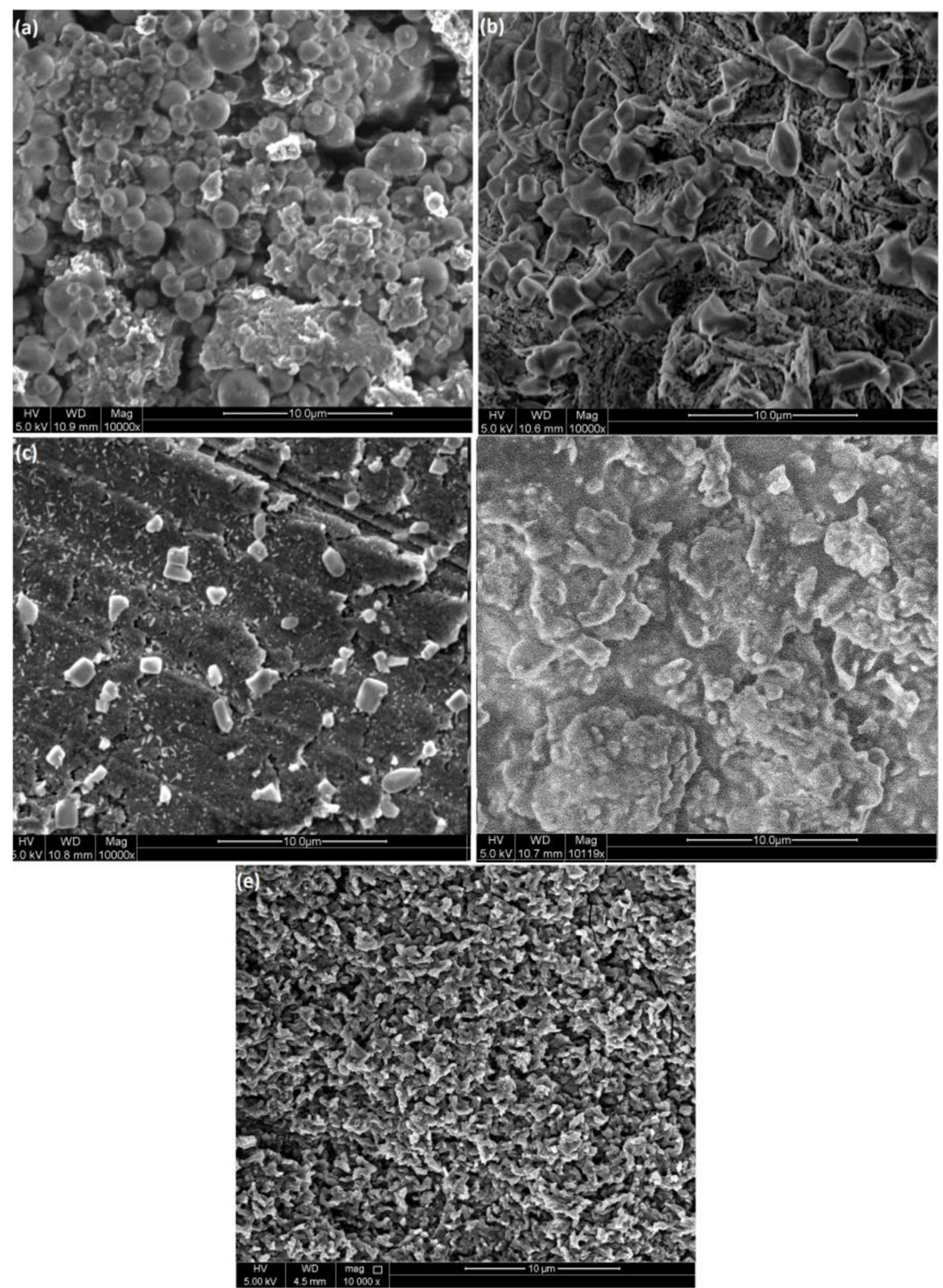

Fig. 2 SEM images of PANI blends with four different polymers a PS, b PVA, $\mathbf{c}$ PVC, $\mathbf{d}$ SA, and e pure PANI

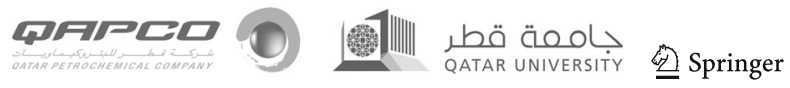


temperature. Standalone films are prepared by casting the green suspension on substrates and left for drying at room temperature.

\subsubsection{PANI-PS blend}

Polymerization of aniline is carried out in acidic solution containing $2 \mathrm{~g}$ of PS in toluene in $0-5{ }^{\circ} \mathrm{C}$. While the sample is being stirred, equimolar amount of ammonium persulfate is added drop wise over a period of $1 \mathrm{~h}$. The solution turns green indicating the formation of PANI and the reaction mixture is stirred continuously for a period of $24 \mathrm{~h}$ maintaining the same temperature. Standalone films are prepared by casting the green suspension on substrates and left for drying at room temperature.

\subsubsection{PANI-PVC blend}

Two grams of PVC is dissolved in tetrahydrofuran (THF) by stirring for $1 \mathrm{~h}$. Then, PANI $(0.25 \mathrm{~g})$ is dispersed in the mixture by sonication for $1 \mathrm{~h}$ at room temperature and stirring for $24 \mathrm{~h}$.

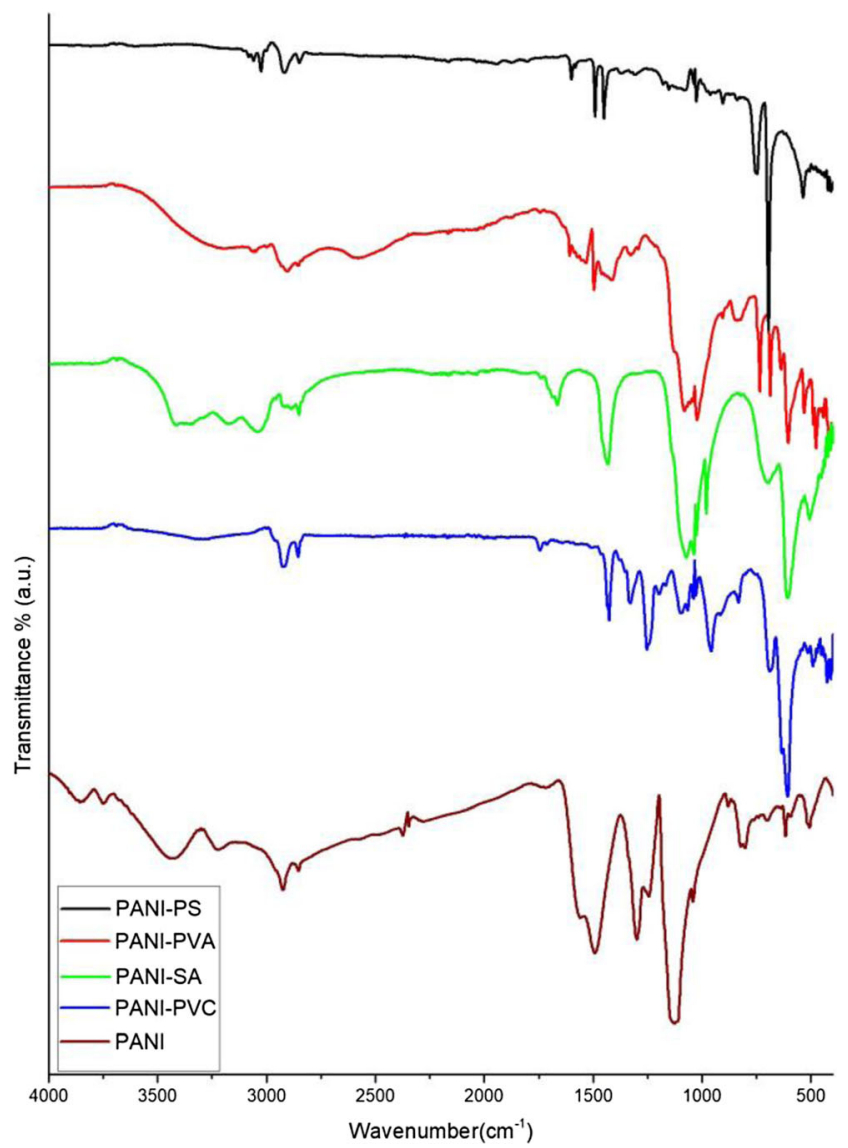

Fig. 3 FTIR spectra of PANI blends with four different polymers, PS, PVA, SA, PVC, and PANI
Subsequently, the blend solution is used to cast films on substrates.

\subsubsection{PANI-SA blend}

Appropriate amount of SA ( $2 \mathrm{~g})$ is dissolved in water by stirring for $1 \mathrm{~h}$. Then PANI $(0.25 \mathrm{~g})$ is dispersed in mixture by sonication for $1 \mathrm{~h}$ at room temperature and stirring for $24 \mathrm{~h}$. Next, the blend solution is used to cast films on glass slides.

\subsection{Characterization techniques}

Scanning electron microscopy (SEM) is employed to study the surface morphology and grain size of PANI using a nano-SEM Nova 450. A Fourier-transform infrared spectrometer (FTIR) (8101 M, Shimadzu) is used in order to study the chemical interaction between the polymers. Thermogravimetric analysis (TGA) and differential scanning calorimetry (DSC) is performed to study the thermal properties of PANI using a Perkin Elmer Pyris TGA and Perkin Elmer Precisely Jade DSC, respectively. The tensile properties are measured with an Instron 4465 (Canton, MA) universal testing machine. The mechanical properties are carried out according to ASTM-D882-12 with crosshead speed of $50 \mathrm{~mm} / \mathrm{min}$ at room temperature. Five specimens are used for each test with gauge length of $100 \mathrm{~mm}$, width of $15 \mathrm{~mm}$, and thickness of $25 \mathrm{~mm}$. Both A.C. and D. C. measurements are investigated to study the electrical properties of all the blend samples. Four probe conductivity are measured using Keithley 2400 source meter measures. For D.C. conductivity all the PANI blend samples are used to coat on interdigital gold electrode fingers using the drop-cast method. Dielectric measurements are performed using a Novocontrol GmbH Concept 40 broadband dielectric spectrometer, and the data are collected over the frequency range $0.1 \mathrm{~Hz}-3 \mathrm{MHz}$ at room temperatures. Samples for electrical measurements are casted and dried directly on a 40-mm diameter stainless steel electrodes; another $20-\mathrm{mm}$ diameter stainless steel electrode is used as a top electrode during testing. The average thickness of the film deposited on different substrates is about $65 \mu \mathrm{m}$ [35].

\section{Results and discussion}

\subsection{SEM picture}

Considering the importance of SEM in the investigation of surface structure and morphology of PANI blends, we have analyzed its performance with utmost attention. Figure $2 \mathrm{a}-\mathrm{e}$ show the SEM images describing morphologies of $\mathrm{HCl}$-doped 
PANI blends and pure PANI. The micrograph images suggest that pure PANI has uniform fibrous morphology. However, it is observed that PANI has not changed much of its structure except in PANI-PVC blend. PANI-PVC has two distinct phases, matrix and the fillers, in the surface morphology indicating its influence on the blend electron transport property. The filler particles have two different sizes with the smaller one and the bigger one are of order $100 \mathrm{~nm}$ and $1 \mu \mathrm{m}$, respectively, whereas the fibrous PANI particles are seen to embed on the polymer matrices with no phase difference in the other three blends. The surface morphology results suggest that both the polymers blend very well in all the samples with uniform distribution. The cohesion between conducting polymers and conventional polymers form well-connected conducting network to conduct electricity though the whole samples. Section 3.6 justifies the formation and different aspects of conducting blends.

\subsection{FTIR results}

The FTIR spectroscopy is a powerful tool for analyzing the molecular structure and their chemical interactions of the constituent materials. Figure 3 shows the FTIR spectra of pure PANI and PANI blend with different polymers viz. PVA, PS, PVC, and SA. The appearance of new peaks in blend FTIR along with changes in existing peaks directly indicate the formation of blend. The positions and observed characteristic bands are tabulated in Table 1

where the values are in good agreement with the theoretical prediction indicating a possible chemical interaction between PANI and polymer (PVA, PS, PVC, SA) molecules forming new bonds between polymer constituents. In all the blends, characteristic peaks of PANI due to the quinoid and benzenoid absorption appear approximately at 1414-1453 and 1595$1680 \mathrm{~cm}^{-1}$, respectively. A possible chemical interaction

Table 1 FTIR peak positions and its corresponding peak assignments for five pure polymers (PANI, PVA, PS, PVC, SA) and four blends (PANI-PVA, PANI-PS, PANI-PVC, PANI-SA)

\begin{tabular}{|c|c|c|c|c|c|c|}
\hline Characteristic peak assignments & References & PANI & PVA & PS & PANI + PVA & PANI + PS \\
\hline $\mathrm{N}-\mathrm{H}$ stretching & {$[31,36-38]$} & 3400 & & & & \\
\hline $\mathrm{O}-\mathrm{H}$ stretching & {$[39,40]$} & & 3357 & & & \\
\hline $\mathrm{C}-\mathrm{H}$ aromatic stretching vibration & {$[41]$} & 2900 & 2925 & $3100-3000$ & 2901 & $3026,3061,3083$ \\
\hline Asymmetrical stretching vibration of $\mathrm{CH}_{2}$ & {$[42]$} & 2920 & & & & 2917 \\
\hline Symmetrical stretching vibration of $\mathrm{CH}_{2}$ & {$[42]$} & & & 2840 & & \\
\hline $\mathrm{C}=\mathrm{O}$ bonds & {$[36]$} & & 1714 & & & \\
\hline $\mathrm{C}-\mathrm{C}$ stretching of benzoid rings & {$[43,44]$} & 1560 & & 1600 & 1559 & 1601 \\
\hline $\mathrm{C}-\mathrm{C}$ stretching of quinoid rings & {$[43,44]$} & 1456 & & 1494 & 1496 & 1492 \\
\hline $\mathrm{C}-\mathrm{N}$ stretching vibration & {$[20,44]$} & 1300 & & & 1479 & \\
\hline Deformation vibration of $\mathrm{CH}_{2}$ of benzene ring & {$[43,44]$} & & 1328 & 1452 & 1304 & 1451 \\
\hline $\mathrm{C}-\mathrm{O}-\mathrm{C}$ bond & {$[36]$} & & 1252 & & & \\
\hline $\mathrm{C}-\mathrm{O}$ stretching vibrations & {$[36]$} & & 1100 & & 1124,1022 & $1081,1038,1027$ \\
\hline Bending vibrations of $\mathrm{C}-\mathrm{H}$ out of plane & {$[40,45]$} & 877 & & & 839 & \\
\hline Bending vibrations of $\mathrm{C}-\mathrm{H}$ in-plane & {$[45,46]$} & 811 & & 757 & 734 & 748 \\
\hline $\mathrm{C}-\mathrm{Cl}$ stretching vibrations & {$[45,46]$} & 503 & & & & 587 \\
\hline Characteristic peak assignments & References & $\mathrm{PVC}$ & SA & $\mathrm{PANI}+\mathrm{PVC}$ & $\mathrm{PANI}+\mathrm{SA}$ & \\
\hline $\mathrm{O}-\mathrm{H}$ stretching vibration & {$[46,47]$} & & 3450 & & 3040 & \\
\hline $\mathrm{C}-\mathrm{H}$ stretch bond & {$[2,23]$} & 2800 & 2890 & 2925 & 2880 & \\
\hline Asymmetric -COO- & {$[46,47]$} & & 1628 & & 1664 & \\
\hline Symmetric -COO- & {$[46,47]$} & & 1419 & & & \\
\hline $\mathrm{C}-\mathrm{H}$ aliphatic bending bond & {$[46,47]$} & 1400 & & 1426 & 1432 & \\
\hline Bending of $\mathrm{C}-\mathrm{H}$ near $\mathrm{Cl}$ & {$[46]$} & 1250 & & 1253 & 1338 & \\
\hline $\mathrm{C}-\mathrm{O}$ stretching vibration of secondary alcohol & {$[46,47]$} & & 1150 & & 1075 & \\
\hline $\mathrm{C}-\mathrm{O}-\mathrm{C}$ stretching vibration of tertiary alcohol & {$[46,47]$} & & 1035 & & 1028 & \\
\hline $\mathrm{C}-\mathrm{C}$ stretch bond & {$[39,40]$} & 1100 & & 1000 & & \\
\hline $\mathrm{C}-\mathrm{Cl}$ stretching & {$[47]$} & 844 & & 888 & & \\
\hline $\mathrm{C}$ is $\mathrm{CH}$ wagging & {$[23]$} & 606 & & 590 & 509 & \\
\hline
\end{tabular}




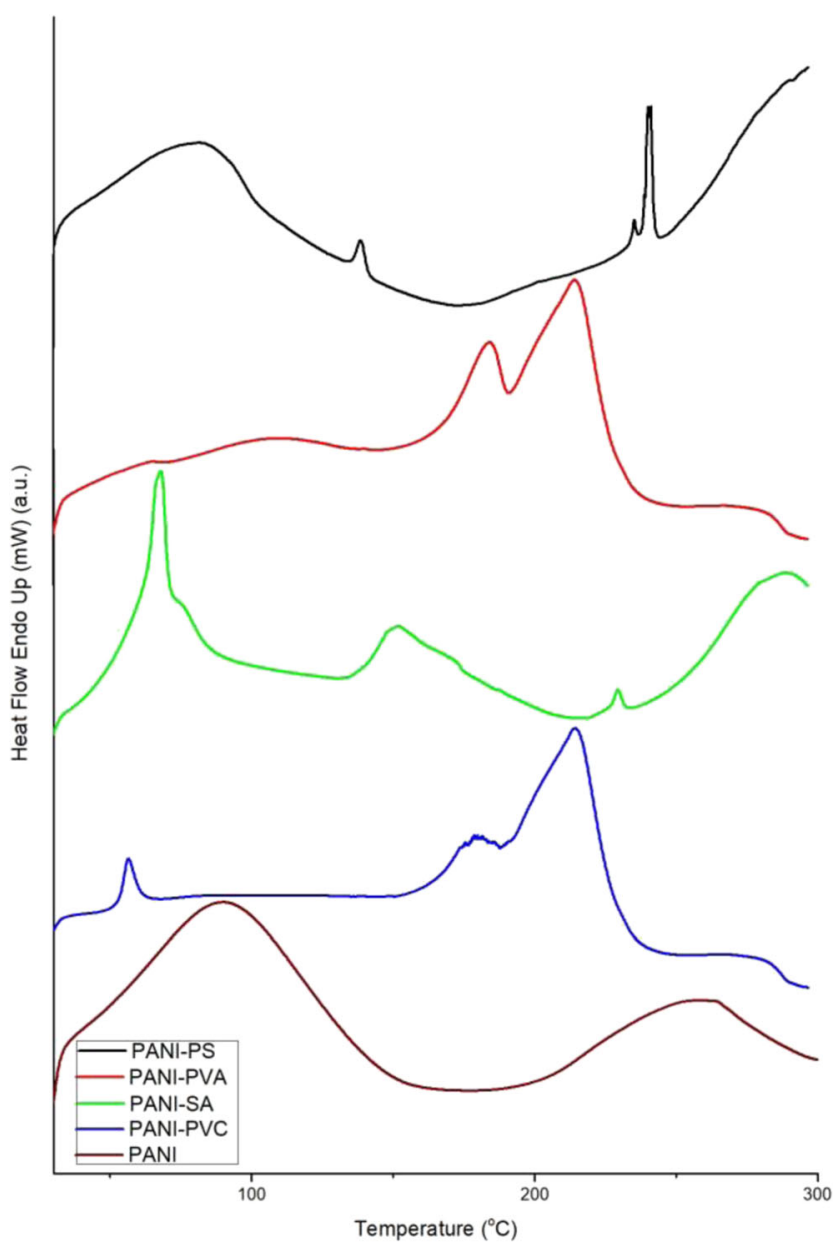

Fig. 4 DSC thermograms for PANI blends with four different polymers, PS, PVA, SA, and PVC, and pure PANI

between PANI and the matrix can be drawn based on these characteristic peaks listed in the table. In case of PANI-PVC, the band observed at $606 \mathrm{~cm}^{-1}$ is assigned to $\mathrm{C}-\mathrm{Cl}$ stretching in pure PVC [31]. The blend of PANI in PVC causes this band to shift to lower wave numbers by $16 \mathrm{~cm}^{-1}$ lower than the pure PVC; similar results have been reported earlier too [31]. The shifting of $\mathrm{C}-\mathrm{Cl}$ band may be ascribed to the chemical interaction (strong dipole-dipole interaction) between $\mathrm{C}-\mathrm{Cl}$ group of PVC and amine of PANI. However, we may see from the table that not many bonds formed between PANI and PVC. In this case, even SEM images also suffice the fact that there are very little conjugation between the polymers.

For PANI-PS blend, the characteristic peaks of PS can be identified as 3026,3061 , and $3082 \mathrm{~cm}^{-1}$, which are related to $\mathrm{C}-\mathrm{H}$ stretching of the benzene ring side chain of PS; the intensity of peaks are less than the pure PS. In case of PANIPVA blend, the peaks around 3357, 2925, 1328, $1100 \mathrm{~cm}^{-1}$ arise due to the stretching vibrations of $\mathrm{O}-\mathrm{H}, \mathrm{C}-\mathrm{H}, \mathrm{CH}_{2}$, and $\mathrm{CO}$ group in PVA [30]. The peaks of the composite films shift to the lower wave numbers compared to pure PVA and PANI. This indicates the formation of hydrogen bond between PVA and PANI. The FTIR spectra peak for SA, pure PANI, and PANI-SA are given in Table 1. The peaks at 1628, 1419, and $1035 \mathrm{~cm}^{-1}$ in the FTIR spectrum of SA are caused by the stretching of -COO- (asymmetric), -COO- (symmetric), and $\mathrm{C}-\mathrm{O}-\mathrm{C}$, respectively. On the other hand, the PANI-SA composite exhibits these characteristic peaks with little blue and red shift to $1664 \mathrm{~cm}^{-1}$ and shoulder peaks at 1432 and $1028 \mathrm{~cm}^{-1}$ of SA [35]. The above results confirm the successful introduction of conducting polymer into the SA surface.

\subsection{DSC analysis}

DSC is a commonly used technique of heat flow in different temperatures to determine the glass transitions, melting, crosslinking reactions, and decomposition. The representatives of DSC curves for pure PANI and PANI blends along with the summary of results are shown in Fig. 4. All the four blends exhibit two endothermic peaks; the 1st peak for all the blends is found between 40 to $130{ }^{\circ} \mathrm{C}$ due to the elimination of solvents used in preparation of polymer blend viz. water (SA, PVA), THF (PVC), toluene (PS), and impurities in the blend. Even pure PANI has two broad endothermic peaks, first peak is around $100{ }^{\circ} \mathrm{C}$ due to the evaporation of the solvents and 2nd broad peak is the degradation of the PANI backbone. No melting peak could be observed for PANI as stated in the literature too; PANI's degradation temperature is lower than its melting temperature [47]. In the blends thermogram, the 2nd endothermic peaks are observed due to the oxidation of polymers at $230{ }^{\circ} \mathrm{C}$ related to PANI-PS blend, $220^{\circ} \mathrm{C}$

related to PANI-PVA, $210{ }^{\circ} \mathrm{C}$ related to PANI-PVC, and $160{ }^{\circ} \mathrm{C}$ related to PANI-SA. The difference in the blend peak positions and intensities from the virgin polymer indicate the chemical changes in the polymer backbones due to blend formation [23, 30, 33]. From the DSC data, it is clear that the blend film exhibits the combined properties of both polymer components.

\subsection{Thermal gravimetric analysis}

The TGA study for pure PANI and PANI blends with four different polymers viz. PVA, PS, PVC, and SA are performed in the range $30-500{ }^{\circ} \mathrm{C}$ at a heating rate of $10{ }^{\circ} \mathrm{C} / \mathrm{min}$ (as shown in Fig. 5). It may be noted that all those experiments are carried out at an inert/neutral atmosphere. A three-step weight loss is observed for the three blends, PANI-PVA, PANI-PS and PANI-SA, whereas pure PANI has two and PANI-PVC has one big and sharp and one very small weight loss peaks. Except PANI-PVC, the first weight loss step in all the thermograms between 40 and $150{ }^{\circ} \mathrm{C}$ is due to the moisture, solvents, free acids, and unreacted monomer, which are used as solvents and dopants during preparation. This loss is about $20 \%$ of the total weight. The second weight loss step lying in $150-350{ }^{\circ} \mathrm{C}$ attributes to loss of dopants from deeper 

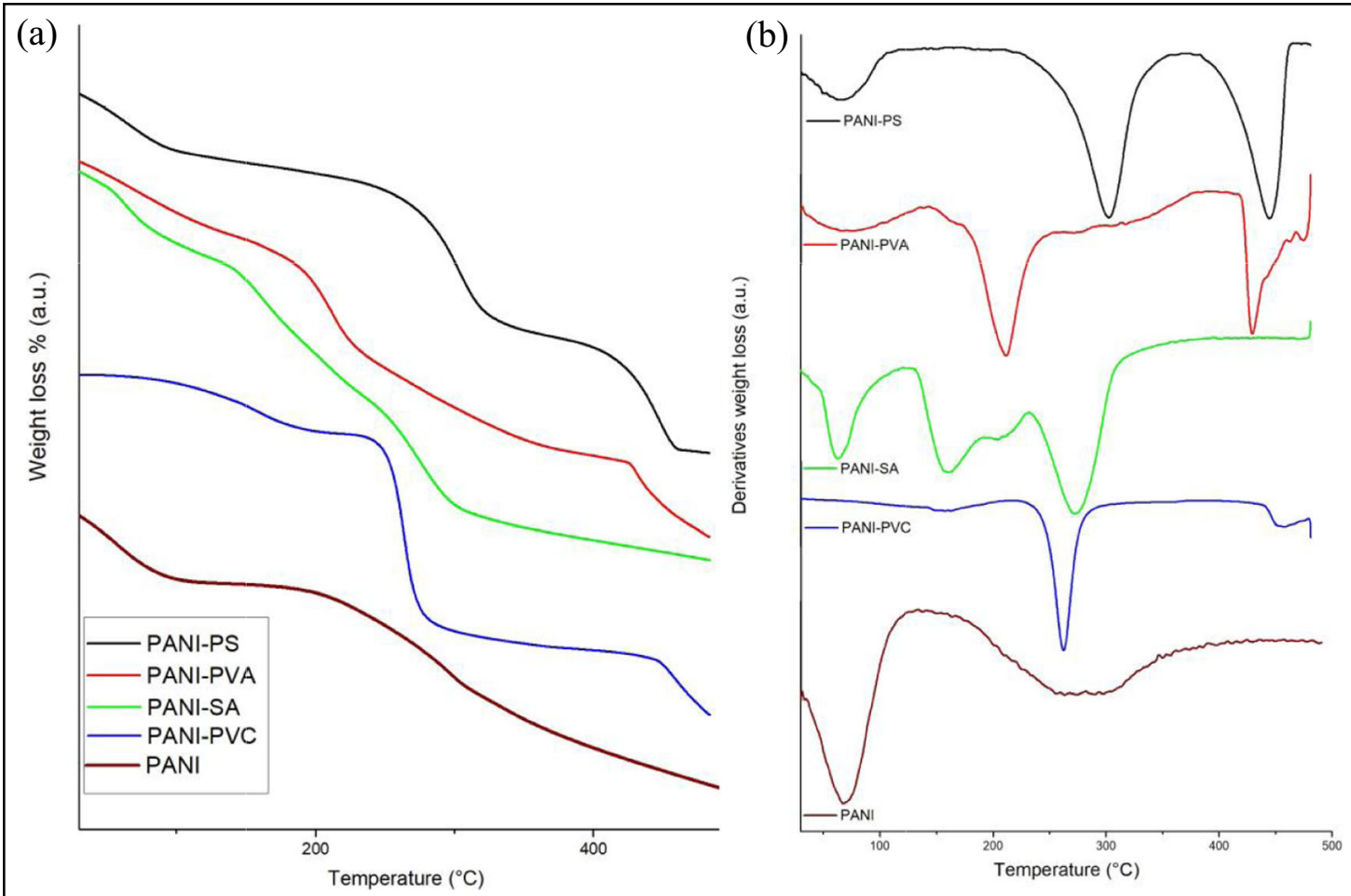

Fig. 5 a TGA thermogram for PANI blends with four different polymers, PVA, PS, PVC, and SA, and pure PANI. b Derivatives plot of TGA for PANI blends with four different polymers, PVA, PS, PVC, and SA, and pure PANI

sites in the material [24, 25], and the degradation of Coulomb attraction between polymers

and the backbone of PANI (since the acid itself starts to evaporate and degrade). Furthermore, the molecular interaction (e.g., hydrogen bonding) among the polymers and PANI is also demolished in this step. Therefore, the major weight loss takes place through this step. In case of PANI-PVC blend, the major weight loss is observed in the first step, which is almost $75 \%$ of the total weight. In this step, PVC that constitutes $88 \%$ of the total weight gets decomposed. The reason

Table 2 Table containing TGA degradation temperature of four polymers blends PANI-PVA, PNAI-PS, PANI-PVC, and PANI-SA

\begin{tabular}{llllll}
\hline \multirow{2}{*}{ Polymer } & Degradation step & \multicolumn{4}{c}{ Final degradation temperatures } \\
\cline { 3 - 6 } & & Onset & Peak & End & $\%$ end product \\
\hline PANI-PVA & 3 & 430 & 451 & 470 & 27 \\
PANI-PS & 3 & 380 & 445 & 462 & 20 \\
PANI-PVC & 2 & 445 & 460 & 480 & 17 \\
PANI-SA & 3 & 230 & 270 & 310 & 35 \\
PANI & 2 & 180 & 265 & 350 & 35 \\
PVA & 1 & 231 & 238 & 337 & 0 \\
PS & 1 & 300 & 441 & 456 & 0 \\
PVC & 1 & 250 & 300 & 367 & 0 \\
SA & 1 & 200 & 247 & 301 & 0 \\
\hline
\end{tabular}

behind this may be the low chemical interaction between two polymers as we also observed from FTIR and SEM results. The third and final step of weight loss is observed in all four blends and five pure polymers; three of them lie in between 350 and $480{ }^{\circ} \mathrm{C}$ as shown in Table 2 . This final weight loss step is attributed as the total thermal weight loss of polymer and their byproducts that are formed during the TGA thermal degradation process $[23,36,41,47]$. The final degradation temperatures for all the blends are different. In case of PANI-PVC blend, the final weight loss is very small; this may be due to the formation of a very stable compound of PANI and PVC but between very few molecules. Even both FTIR results and SEM images suggest the similar finding.

\subsection{Tensile measurement}

The mechanical properties, such as tensile strength, percentage of elongation at break for pure polymers, and PANI blends, are tabulated in Table 3. When the mechanical properties of the pure polymers are compared with that of its corresponding blends, it is observed that the presence of PANI causes the variation in the parameters. A significant reduction in the tensile strength may be observed with the addition of PANI in the blend. This reduction can be explained as follows: PANI possesses a very stiff polymer backbone from the presence of aromatic rings and the usual formation of double bonds resulting in an extremely brittle polymer $[42,48]$. The 
Table 3 Table containing tensile strength, Young's modulus, and $\%$ elongation of the pure polymers (PANI, PVA, PS, PVC, SA) blend films (PANI-PVA, PANI-PS, PANI-PVC, PANI-SA)

\begin{tabular}{lcclll}
\hline Polymer & $\begin{array}{l}\text { Polymer } \\
\text { loading }(\%)\end{array}$ & $\begin{array}{l}\text { Polyaniline } \\
\text { loading }(\%)\end{array}$ & $\begin{array}{l}\text { Tensile strength } \\
(\mathrm{MPa})\end{array}$ & $\begin{array}{l}\text { Young's } \\
\text { modulus (MPa) }\end{array}$ & $\begin{array}{l}\text { Percentage } \\
\text { elongation (\%) }\end{array}$ \\
\hline PANI & 0 & 100 & - & & - \\
PVA & 100 & 0 & 26.44 & 136.33 & 316.33 \\
PS & 100 & 0 & 13.30 & 1412.8 & 3.46 \\
PVC & 100 & 0 & 23.72 & 1788.5 & 1.99 \\
SA & 100 & 0 & 20.35 & 1566.7 & 8.14 \\
PANI-PVA & 88 & 12 & 2.18273 & 198.39 & 62 \\
PANI-PS & 88 & 12 & 0.60216 & 2272.7 & 1 \\
PANI-PVC & 88 & 12 & 0.86800 & 5486 & 0.6 \\
PANI-SA & 88 & 12 & 1.6840 & 1803.4 & 2.57 \\
\hline
\end{tabular}

presence of excess unbounded dopant in the blend, which acts as non-reinforcing filler, weakens the interaction (secondary interaction) between PANI and polymers. Table 3 reveals the drastic reduction in the percentage of elongation of all types of blends as expected. PANI-PVC blend is seen to have the most brittle and highest Young's modulus, whereas PANI-PVA does have the highest ductility and smallest Young's modulus.

\subsection{Conductivity measurement}

Four probe electrical measurement of blends deposited on interdigital gold electrode are used to measure D.C. conductivity. The conductivity results are tabulated in Table 4. As observed from the table, the variation in conductivity values are due to the difference in distribution of conducting fillers within the polymer matrix. As we can see from the SEM images, PANI-PVA has the most uniform distribution that leads to the highest conductivity among the blends.

Variation of AC conductivity of PANI blends with frequency for different temperatures is shown in Fig. 6. The frequency dependence of conductivity is strongly related to the behavior of conduction phenomenon and charge transport in conducting blends. The AC conductivity sums over all the dissipative effects of the material.

An increase in AC conductivity with frequency and temperature dependence indicates that there may be charge carriers, which are transported by hopping through the defect sites along the polymer chain [49]. In addition, the increase in electrical conduction with increasing temperatures is due to the build-up of ordered polycondensed rings, which allow charge transport. This temperature dependence of conductivity at higher

Table 4 D. C. conductivity of four PANI blends with PVA, PS, PVC, and SA

Name of the blends PANI-PVA PANI-PS PANI- PANI-SA PVC

Conductivity S/cm $\quad 1.22 \times 10^{-4} \quad 9.27 \times 10^{-5} \quad 1.8 \times 10-9 \quad 2.97 \times 10^{-6}$ temperatures suggests that the variable range hopping of charge carriers may occur in the blends. The AC conductivity behavior of PANI-PVA, PANI-PS, and PANI-SA are independent of frequency, whereas PANI-PVC shows frequency dependence. However, the AC conductivity behavior clearly states that PANI-PVA, PANI-PS, and PANI-SA have conducting nature and PANI-PVC has insulating nature.

Room temperature $\left(28^{\circ} \mathrm{C}\right) \mathrm{AC}$ conductivity behavior for all polymer samples is studied in Fig. 7. For the three PANI blends (PVA, PS, and SA), conductivity forms a wide plateau to include most of the measured frequency ranges. On the other hand, PANI-PVC does not show any plateaus and its gradual increase with increasing frequency is mainly due to the motion of the PANI and PVC chain dipoles (relaxation region) [50]. The SEM, FTIR, and TGA also have an agreement with the formation of conducting network of PANI within blends of PVA, PS, and SA.

\section{Conclusion}

PANI blends have been successfully prepared with four different polymers (viz., PS, PVA, PVC, and SA). In this study, SEM, FTIR, TGA, DSC, and tensile strength are used to characterize the resulted blends, whereas the electrical measurements are obtained by A. C. conductivity measurement and four probe conductivity. All the characterization results concludes the formation of a wide variety of conducting blends. The change in polymer indicates a significant effect on morphology and structure of the blends. From SEM, FTIR, and TGA, analysis results indicate formation of strong chemical bonding between PANI and PVA. This results into high electrical conductivity up to the order of $10^{-2} \mathrm{~S} / \mathrm{cm}$. In contrary, SEM, FTIR, and TGA investigation outcomes show PANI-PVC immiscible blend, which resulted into a very low electrical conductivity. The preparation method for the PANI blend investigated in this work has resulted in the production of freestanding flexible thermoplastic polymers with wide ranges of conductivities. The property analysis of four different samples leads to varying conductivity mechanisms and varying 

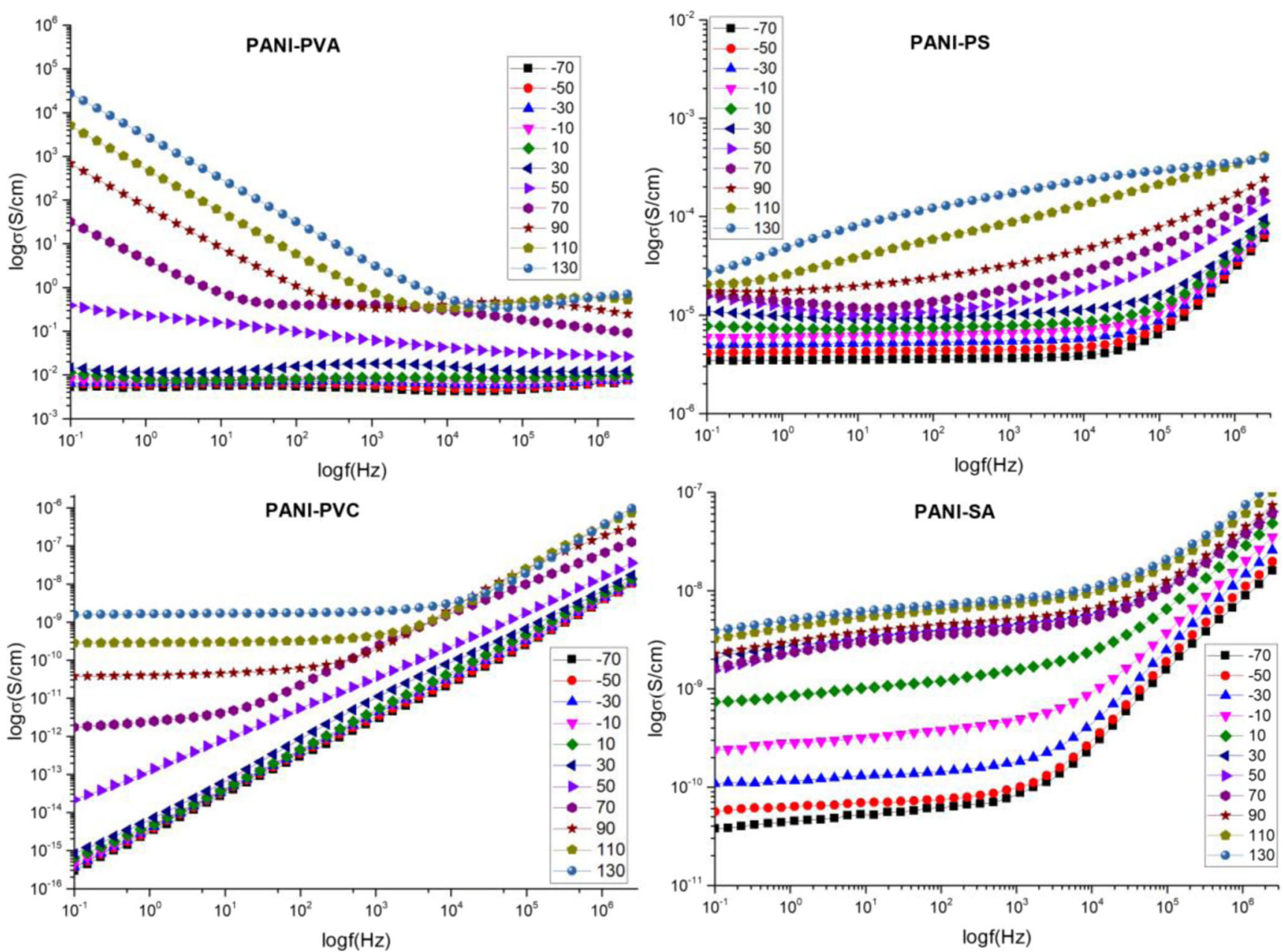

Fig. 6 A. C. conductivity as a function of frequency at PANI blends with four different polymers, PVA, PS, PVC, and SA, at different temperatures

conductivity ranges with respect to frequency in these blends; as the electronic industry needs varying conductivity for different purposes, therefore, we believe that these blends could find

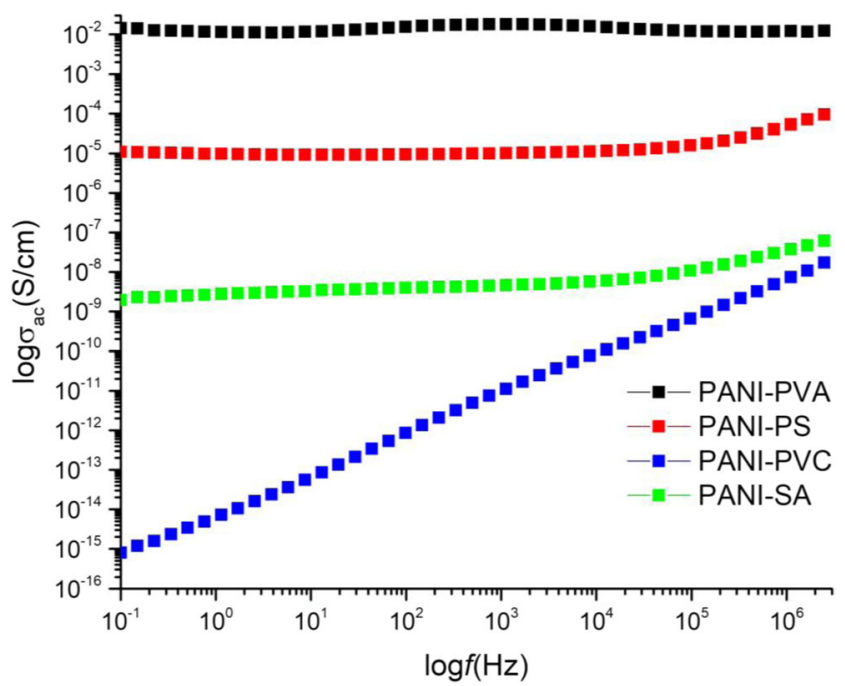

Fig. 7 Plot of room temperature A. C. conductivity as a function of frequency for PANI blends with PVA, PS, PVC, and SA ample number of electronic applications such as electronics devices, textiles, and packaging industries.

Acknowledgments Open Access funding provided by the Qatar National Library. The authors express their deep sense of gratitude to students of Al-Bairaq for their contribution in the experimental work. Authors also like to acknowledge the Office of the Vice President for Research and Center for Advanced Materials. The authors also acknowledge the reviewers for their deep and thorough review of the manuscript that helped the authors to improve the paper largely.

Open Access This article is distributed under the terms of the Creative Commons Attribution 4.0 International License (http:// creativecommons.org/licenses/by/4.0/), which permits unrestricted use, distribution, and reproduction in any medium, provided you give appropriate credit to the original author(s) and the source, provide a link to the Creative Commons license, and indicate if changes were made.

\section{References}

1. D. Ponnamma, A. Erturk, H. Parangusan, K. Deshmukh, M.B. Ahamed, M.A.A. Al-Maadeed, Stretchable quaternary phasic PVDF-HFP nanocomposite films containing graphene-titaniaSrTiO3 for mechanical energy harvesting. Emergent Mater 1, 5565 (2018). https://doi.org/10.1007/s42247-018-0007-z

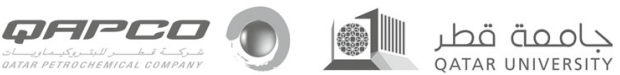


2. M. Mrlik, P. Sobolciak, I. Krupa, P. Kasak, Light-controllable viscoelastic properties of a photolabile carboxybetaine ester-based polymer with mucus and cellulose sulfate. Emergent Mater 1, 3545 (2018). https://doi.org/10.1007/s42247-018-0004-2

3. A.R. Jiménez, S.H. López, E.V. Santiago, Conductive polymeric composites based on multiwalled carbon nanotubes and linseed oil functionalized and cross-linked with diacetylenes from propargyl alcohol. J. Nanomater. 2015, 7 (2015)

4. A.K. Solarajan, V. Murugadoss, S. Angaiah, High performance electrospun $\mathrm{PVdF}-\mathrm{HFP} / \mathrm{SiO}_{2}$ nanocomposite membrane electrolyte for Li-ion capacitors. J. Appl. Polym. Sci. 134 (2017). https://doi. org/10.1002/APP.45177

5. W. Brostow, S. Lohse, X. Lu, A.T. Osmanson, Nano- $\mathrm{Al}(\mathrm{OH}) 3$ and $\mathrm{Mg}(\mathrm{OH})_{2}$ as flame retardants for polypropylene used on wires and cables. Emergent Mater 1, 1-12 (2018). https://doi.org/10.1007/ s42247-018-0019-8

6. A. Popelka, P. Sobolčiak, M. Mrlík, Z. Nogellova, I. Chodák, M. Ouederni, M.A. Al-Maadeed, I. Krupa, Foamy phase change materials based on linear low-density polyethylene and paraffin wax blends. Emergent Mater 1, 47-54 (2018). https://doi.org/10.1007/ s42247-018-0003-3

7. K. Müller, E. Bugnicourt, M. Latorre, et al., Review on the processing and properties of polymer nanocomposites and nanocoatings and their applications in the packaging, automotive and solar energy fields. Nann T, ed. Nanomaterials 7, 47 (2017)

8. T. Meng, C. Yi, L. Liu, A. Karim, X. Gong, Enhanced thermoelectric properties of two-dimensional conjugated polymers. Emergent Mater 1, 67-76 (2018). https://doi.org/10.1007/s42247-018-0002-4

9. S. Geetha, K.K. Satheesh, K. Chepuri, R.K. Rao, M. Vijayan, D.C. Trivedi, EMI shielding: methods and materials - a review. J. Appl. Polym. Sci. 112, 2073-2086 (2009). https://doi.org/10.1002/app. 29812

10. D.C. Trivedi, S.K. Dhawan, Antistatic applications of conducting polyaniline. Polym. Adv. Technol. 4, 335-340 (1993). https://doi. org/10.1002/pat.1993.220040503

11. V. Elayappan, V. Murugadoss, S. Angaiah, Z. Fei, P.J. Dyson, Development of a conjugated polyaniline incorporated electrospun poly(vinylidene fluoride-co-hexafluoropropylene) composite membrane electrolyte for high performance dye-sensitized solar cells. J. Appl. Polym. Sci. 132 (2015). https://doi.org/10.1002/APP.42777

12. K. Saranya, M. Rameez, A. Subramania, Developments in conducting polymer based counter electrodes for dye-sensitized solar cells - an overview. Eur. Polym. J. 66, 207-227 (2015)

13. A.K. Solarajan, V. Murugadoss, S. Angaiah, Dimensional stability and electrochemical behaviour of $\mathrm{ZrO} 2$ incorporated electrospun PVdF-HFP based nanocomposite polymer membrane electrolyte for Li-ion capacitors. Sci. Rep. 7, 45390 (2017)

14. N. Abdullah, N. Yusof, A.F. Ismail, F.E.C. Othman, J. Jaafar, L.W. Jye, W.N.W. Salleh, F. Aziz, N. Misdan, Effects of manganese(VI) oxide on polyacrylonitrile-based activated carbon nanofibers (ACNFs) and its preliminary study for adsorption of lead(II) ions. Emergent Mater 1, 89-94 (2018). https://doi.org/10.1007/s42247018-0008-y

15. A. Nagaraj, D. Govindaraj, M. Rajan, Magnesium oxide entrapped Polypyrrole hybrid nanocomposite as an efficient selective scavenger for fluoride ion in drinking water. Emergent Mater 1, 25-33 (2018). https://doi.org/10.1007/s42247-018-0001-5

16. C. Jo, D. Pugal, I.K. Oh, K.J. Kim, K. Asaka, Recent advances in ionic polymer-metal composite actuators and their modeling and applications. Prog. Polym. Sci. 38, 1037-1066 (2003). https://doi. org/10.1016/j.progpolymsci.2013.04.003

17. M. Yu, H. Shen, Z.D. Dai, Manufacture and performance of ionic polymer-metal composites. J. Bionic Eng. 4, 143-149 (2007). https://doi.org/10.1016/S1672-6529(07)60026-2

18. K. Balakrishnan, M. Kumar, S. Angaiah, Synthesis of polythiophene and its carbonaceous nanofibers as electrode materials for asymmetric supercapacitors. Adv. Mater. Res. 938, 151-157 (2014)

19. K. Hu, D.D. Kulkarni, I. Choi, V.V. Tsukruk, Graphene-polymer nanocomposites for structural and functional applications. Prog. Polym. Sci. 39, 1934-1972 (2014). https://doi.org/10.1016/j. progpolymsci.2014.03.001

20. R. Ansar, Polypyrrole conducting electroactive polymers: synthesis and stability studies. E- J. Chem. 3, 186-201 (2006)

21. P. Banerjee, B.M. Mandal, Blends of HCl-doped polyaniline nanoparticles and poly(vinyl chloride) with extremely low percolation threshold - a morphology study. Synth. Met. 74, 257-261 (1995)

22. S. Virji, J. Huang, R.B. Kaner, B.H. Weiller, Polyaniline nanofiber gas sensors: examination of response mechanisms. Nano Lett. 4, 491-496 (2001)

23. S.H. Hosseini, A.A. Entezami, Preparation and characterization of polyaniline blends with polystyrene, poly(vinyl chloride) and poly(vinyl acetate) for toxic gas sensors. Polym. Adv. Technol. 12, 482$493(2001)$

24. M.A.A. El-Ghaffar, A.M. Youssef, A.A.A. El-Hakim, Polyaniline nanocomposites via in situ emulsion polymerization based on montmorillonite: preparation and characterization. Arab. J. Chem. 8, 771-779 (2015). https://doi.org/10.1016/j.arabjc.2014.01.001

25. T.S. Gaaz, A.B. Sulong, M.N. Akhtar, A.A.H. Kadhum, A.B. Mohamad, A.A. Al-Amiery, Properties and applications of polyvinyl alcohol, halloysite nanotubes and their nanocomposites. Molecules 20, 22833-22847 (2015). https://doi.org/10.3390/ molecules201219884

26. R.D. Kale, Y.M. Tejasvi, P.T. Potdar, Paper-reinforced sodium alginate/carboxyl methyl cellulose-based bio-composite films. J. Plast. Film Sheeting 34, 179-195 (2018). https://doi.org/10.1177/ 8756087917715675

27. A.R.V. Ferreira, V.D. Alves, I.M. Coelhoso, Polysaccharide-based membranes in food packaging applications. Membranes 6, 22 (2016). https://doi.org/10.3390/membranes6020022

28. H.P. Staudinger, H.M. Stanley, The properties and applications of polystyrene resins. J. Chem. Technol. Biotechnol. 57, 141-144 (1938). https://doi.org/10.1002/jctb.5000570702

29. S.A. Chen, G.W. Hwang, Structures and properties of the watersoluble self-acid-doped conducting polymer blends: sulfonic acid ring-substituted polyaniline/poly(vinyl alcohol) and poly(anilineco-N-propanesulfonic acid aniline)/poly(vinyl alcohol). Polymer 38, 3333-3346 (1997)

30. M. Beltran, A. Marcilla, Fourier transform infrared spectroscopy applied to the study of PVC decomposition. Eur. Polym. J. 33, 1135-1142 (1997)

31. A.B. Afzal, M.J. Akhtar, M. Nadeem, M.M. Hassan, Dielectric and impedance studies of DBSA doped polyaniline/PVC composites. Curr. Appl. Phys. 10, 601-606 (2010). https://doi.org/10.1016/j. cap.2009.08.004

32. I. da Silva Guimarães, A.A. Hidalgo, H.N. da Cunha, L. de Miranda Santos, J.A.V. dos Santos, J.R. dos Santos Júnior, Thermal and morphological characterization of conducting, polyaniline/ polystyrene blends. Synth. Met. 162, 705-709 (2012). https://doi. org/10.1016/j.synthmet.2012.02.015

33. Y. Yu, S. Zhihuai, S. Chen, C. Bian, W. Chen, G. Xue, Facile synthesis of polyaniline-sodium alginate nanofibers. Langmuir 22, 3899-3905 (2006). https://doi.org/10.1021/la051911v

34. J. Bhadra, A. Popelka, A. Abdulkareem, M. Lehocky, P. Humpolicek, N. Al-Thani, Effect of humidity on the electrical properties of the silver-polyaniline/polyvinyl alcohol nanocomposites. Sensors Actuators A Phys. (2019). https://doi.org/10.1016/j. sna.2019.01.012

35. P. Li, Y.N. Dai, J.P. Zhang, A.Q. Wang, Q. Wei, Chitosan-alginate nanoparticles as a novel drug delivery system for nifedipine. Int. J. Biomed. Sci. 4, 221-228 (2008) 
36. S. Palaniappan, B. Rajender, A novel polyaniline-silver nitrate-ptoluenesulfonic acid salt as recyclable catalyst in the stereo selective synthesis of b- amino ketones: "one-pot" synthesis in water medium. Adv. Synth. Catal. 352, 2507-2514 (2010)

37. J.M. Gohil, A. Bhattacharya, P. Ray, Studies on the crosslinking of poly (vinyl alcohol). J. Polym. Res. 13, 161-169 (2006)

38. X. Zhang, J. Zhu, N. Haldolaarachchige, J. Ryu, D.P. Young, S. Wei, Z. Guo, Synthetic process engineered polyaniline nanostructures with tunable morphology and physical properties. Polymer 53, 2109-2120 (2012)

39. L.H. Dao, M. Leclerc, J. Guay, J.W. Chevalier, Synthesis and characterization of substituted poly(anilines). Synth. Met. 29, 377-382 (1989)

40. Y.H. Park, C.R. Park, Preparation of conducting polyacrylonitrile/ polyaniline composite films by electrochemical synthesis and their electroactivity. Synth. Met. 118, 187-192 (2001)

41. R.C. Patil, S. Radhakrishnan, K. Ogura, Effect of dopant ions on thermal stability of conducting poly(o-phenitidine). Polym. Degrad. Stab. 73, 7-13 (2001)

42. R. Sattar, A. Kausar, M. Siddiq, Thermal, mechanical and electrical studies of novel shape memory polyurethane/polyaniline blends. Chin. J. Polym. Sci. 33, 1313-1324 (2015)

43. Y.H. Park, H.C. Shin, Y. Lee, Y. Son, D.H. Baik, Electrochemical preparation of polypyrrole copolymer films from pspms precursor. Macromolecules 32, 4615-4618 (1999)

44. A.G. MacDiarmid, S.K. Monokar, J.G. Masters, Y. Sun, H. Wei, A.J. Epstein, Polyaniline: synthesis and properties of pernigraniline base. Synth. Met. 41, 621-626 (1991)
45. V. Jousseaume, M. Morsli, A. Bonnet, Aging of electrical conductivity in conducting polymer films based on polyaniline. J. Appl. Phys. 88, 960-966 (2000)

46. W. Pan, S.L. Yang, G. Li, J.M. Jiang, Electrical and structural analysis of conductive polyaniline/polyacrylonitrile composites. Eur. Polym. J. 41, 2127-2133 (2005)

47. S. Palaniappan, B.H. Narayana, Conducting polyaniline salts: thermogravimetric and differential thermal analysis. Thermochim. Acta 237, 91-97 (1994)

48. G.M.O. Barra, L.B. Jacques, R.L. Orefice, J.R.G. Carneiro, Processing, characterization and properties of conducting polyaniline-sulfonated SEBS block copolymers. Eur. Polym. J. 40, 2017-2023 (2004)

49. S. Sravanan, M.R. Anantharaman, S. Venkatachalam, Structural and electrical studies on tetrameric cobalt phthalocyanine and polyaniline composites. Mater. Sci. Eng. B 135, 113-119 (2006)

50. N. Al-Thani, M.K. Hassan, J. Bhadra, Polyaniline/polystyrene blends: in-depth analysis of the effect of sulfonic acid dopant concentration on ac conductivity using broadband dielectric spectroscopy. Int. J. Polym. Sci. 2018, 1416531, 9 pages (2018). https://doi. org/10.1155/2018/1416531 